OPEN

\title{
Alice in Wonderland syndrome
}

\section{A systematic review}

\author{
Jan Dirk Blom, MD, PhD
}

\begin{abstract}
Purpose of review: To summarize the literature on Alice in Wonderland syndrome (AIWS), a disorder characterized by distortions of visual perception, the body schema, and the experience of time. Recent findings: On the basis of 169 published case descriptions, the etiology of AIWS is divided into 8 main groups, with neurologic disorders affecting mostly adults and elderly patients and encephalitides affecting mostly patients aged $\leq 18$ years. Symptoms of AIWS are also experienced in the general population, with up to $30 \%$ of adolescents reporting nonclinical symptoms. Summary: In clinical cases of AIWS, auxiliary investigations (including blood tests, EEG, and brain MRI) are strongly advised. Treatment should be directed at the suspected underlying condition, although reassurance that the symptoms themselves are not harmful seems to suffice in about $50 \%$ of the cases. International classifications such as the DSM and ICD should consider placing the syndrome on their research agenda. Neurol Clin Pract 2016;6:259-270
\end{abstract}

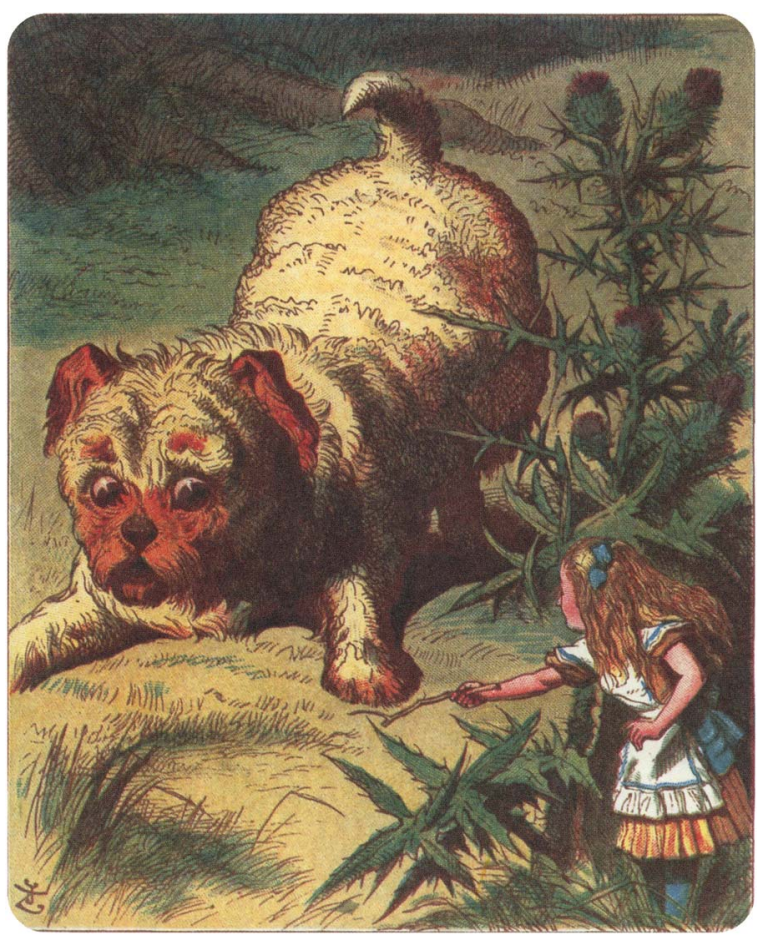

$\mathrm{F}$ irst described in 1955, Alice in Wonderland syndrome (AIWS) is a perceptual disorder characterized by distortions of visual perception (metamorphopsias), the body schema, and the experience of time. The name refers to Lewis Carroll's well-known children's book Alice's Adventures in Wonderland, ${ }^{1}$ in which Alice feels (among other things) her body growing both larger and smaller (figures 1 and 2). After 60 years of relative obscurity, AIWS has begun to receive scientific attention. This renewed interest is in part because of the current possibility to explore the brain's networks responsible for mediating its symptoms with the aid of functional imaging techniques. ${ }^{2-6}$ AIWS symptoms have both diagnostic and therapeutic consequences that differ substantially from those in schizophrenia spectrum disorders and other

Parnassia Psychiatric Institute, The Hague; Leiden University, Leiden; and Department of Psychiatry, University of Groningen, Groningen, the Netherlands.

Funding information and disclosures are provided at the end of the article. Full disclosure form information provided by the author is available with the full text of this article at Neurology.org/cp. The Article Processing Charge was paid by the author.

This is an open access article distributed under the terms of the Creative Commons Attribution-NonCommercialNoDerivatives License 4.0 (CC BY-NC-ND), which permits downloading and sharing the work provided it is properly cited. The work cannot be changed in any way or used commercially.

Correspondence to: jd.blom@parnassia.nl 
Figure 1 Alice experiences total-body macrosomatognosia. Illustration by John Tenniel (1865)

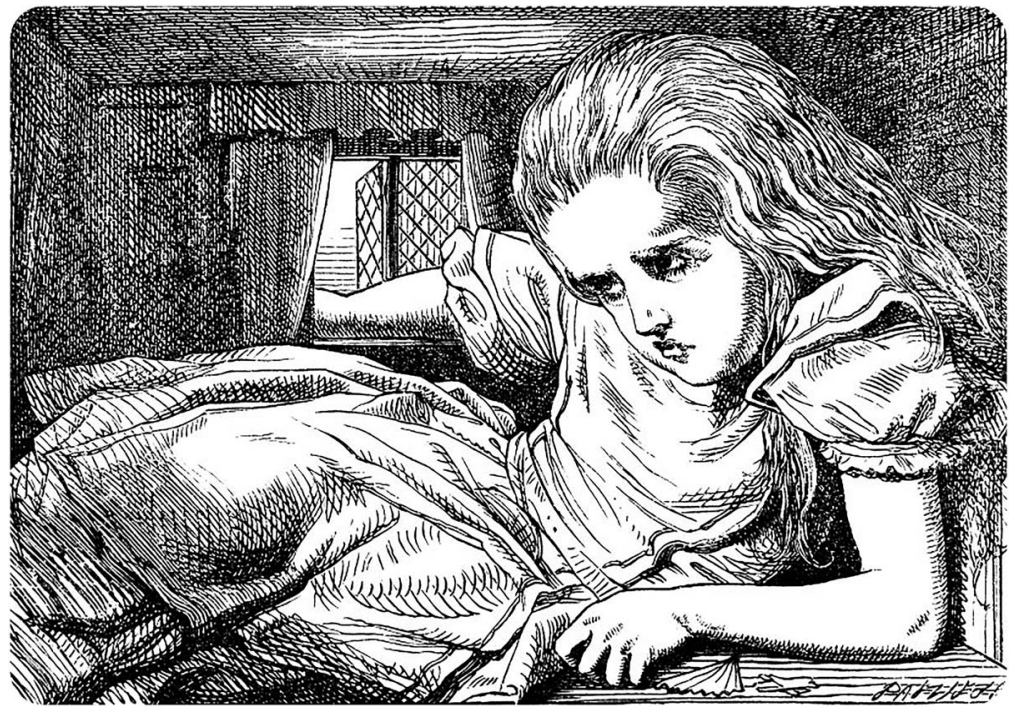

hallucinatory syndromes. This article presents an overview of the literature on AIWS published over the past 60 years and summarizes its implications for clinical practice and research.

\section{METHODS}

A systematic literature search was carried out in PubMed (until June 2015) using the search terms "Alice in Wonderland syndrome," "syndrome of Alice in Wonderland," and variants thereof. Included were articles in the English, Dutch, German, French, Spanish, and Italian languages. All cross-references were checked systematically. In this

Figure 2 (A) Alice experiences partial macrosomatognosia, and (B) Alice experiences totalbody microsomatognosia. Illustrations by John Tenniel (1890).
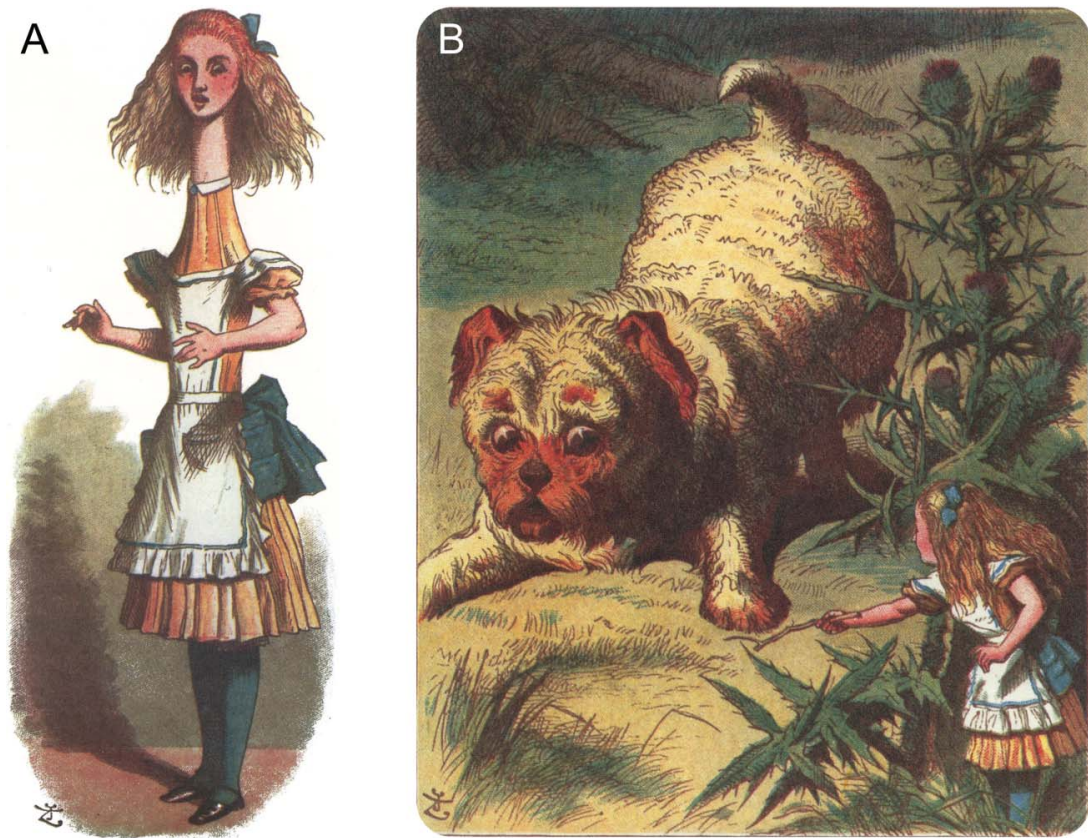
Table 1 Conditions in which Alice in Wonderland syndrome has been described in the literature, with the numbers of case descriptions per age group

\section{Condition}

Infectious diseases

Coxsackie B1 virus encephalitis

Cytomegalovirus

Epstein-Barr virus encephalitis

(mononucleosis infectiosa)

Influenza A virus encephalitis

Lyme neuroborreliosis

Scarlet fever

Typhoid encephalopathy

Varicella-zoster encephalitis

CNS lesions

Acute disseminated encephalomyelitis

Cavernous angioma

Cerebral arteriosclerosis

Cerebral thrombosis

Cerebral hemorrhage

Cerebral infarction

Brain tumor

Microembolization after open heart surgery

Robin Hood syndrome

Traumatic encephalopathy

Wallenberg syndrome

PNS lesions

Eye disease

Middle-ear disease

Paroxysmal neurologic disorders

Epilepsy

Headache with neurologic deficits and CSF lymphocytosis

Migraine

Psychiatric disorders

Depressive disorder

Derealization/depersonalization disorder

Misidentification syndrome

Schizophrenia

Schizoaffective disorder

Medication

5- $\mathrm{HT}_{2}$ antagonist

Dextromethorphan
No. of case reports (\%) in total group $(\mathrm{N}=166)$

38 (22.9)

2 (1.2)

$1(0.6)$

$26(15.7)$

$3(1.8)$

$1(0.6)$

$1(0.6)$

$1(0.6)$

$3(1.8)$

$13(7.8)$

$1(0.6)$

$1(0.6)$

$1(0.6)$

$1(0.6)$

$1(0.6)$

$1(0.6)$

$1(0.6)$

$1(0.6)$

$1(0.6)$

$3(1.8)$

$1(0.6)$

$2(1.2)$

1 (0.6)

1 (0.6)

51 (30.7)

5 (3.0)

$1(0.6)$

45 (27.1)

6 (3.6)

2 (1.2)

$1(0.6)$

$1(0.6)$

$1(0.6)$

1 (0.6)

$10(6.0)$

1 (0.6)

$1(0.6)$
No. of case reports (\%) in patients aged $\leq 18 \mathrm{y}$ 36 (21.7)

2 (1.2)

1 (0.6)

24 (14.5)

3 (1.8)

1 (0.6)

1 (0.6)

1 (0.6)

3 (1.8)

3 (1.8)

$-$

$-$

$-$

$-$

$-$

$-$

$-$

$-$

$-$

-

3 (1.8)

-

$-$

$-$

$-$

33 (19.9)

4 (2.4)

-

$29(17.5)$

-

-

$-$

$-$

$-$

$-$

$-$

4 (2.4)

-

$1(0.6)$
16 (9.6)

No. of case reports (\%) in patients aged $>18 \mathrm{y}$

2 (1.2)

-

2 (1.2)

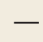

$-$

$-$

-

$10(6.0)$

1 (0.6)

1 (0.6)

$1(0.6)$

$1(0.6)$

$1(0.6)$

1 (0.6)

$1(0.6)$

$1(0.6)$

$1(0.6)$

$-$

$1(0.6)$

2 (1.2)

$1(0.6)$

1 (0.6)

18 (10.8)

1 (0.6)

$1(0.6)$

6 (3.6)

2 (1.2)

1 (0.6)

$1(0.6)$

1 (0.6)

$1(0.6)$

6 (3.6)

$1(0.6)$

$-$ 
Table 1 Continued

\begin{tabular}{|c|c|c|c|}
\hline Condition & $\begin{array}{l}\text { No. of case reports }(\%) \text { in } \\
\text { total group }(N=166)\end{array}$ & $\begin{array}{l}\text { No. of case reports }(\%) \text { in } \\
\text { patients aged } \leq 18 \mathrm{y}\end{array}$ & $\begin{array}{l}\text { No. of case reports }(\%) \\
\text { in patients aged }>18 y\end{array}$ \\
\hline $\begin{array}{l}\text { Cough syrup (containing dihydrocodeine } \\
\text { and } D L-\text { methylephedrine) }\end{array}$ & $1(0.6)$ & - & $1(0.6)$ \\
\hline Montelukast & $1(0.6)$ & $1(0.6)$ & - \\
\hline Oseltamivir & $1(0.6)$ & $1(0.6)$ & - \\
\hline Substance-induced (HPPD) & $10(6.0)$ & $1(0.6)$ & $9(5.4)$ \\
\hline Amanita muscaria & $1(0.6)$ & - & 1 (0.6) \\
\hline Amphetamines & $1(0.6)$ & - & $1(0.6)$ \\
\hline LSD & $1(0.6)$ & - & $1(0.6)$ \\
\hline MDMA & $1(0.6)$ & - & $1(0.6)$ \\
\hline Mescaline & $1(0.6)$ & - & $1(0.6)$ \\
\hline Toluene-containing solvent & 1 (0.6) & - & 1 (0.6) \\
\hline Trichlorethylene & $1(0.6)$ & - & $1(0.6)$ \\
\hline Miscellaneous & 5 (3.0) & - & 5 (3.0) \\
\hline Hypnagogic state & $1(0.6)$ & - & $1(0.6)$ \\
\hline Hypnopompic state & $1(0.6)$ & - & $1(0.6)$ \\
\hline
\end{tabular}

article, symptoms of AIWS experienced by patients diagnosed with a neurologic, psychiatric, or other medical condition are referred to as "clinical," and symptoms of AIWS experienced by individuals in the general population who have not sought medical attention are referred to as "nonclinical."

\section{RESULTS}

The search terms yielded 130 hits in PubMed. Of these, 59 articles had AIWS as their main subject. Via cross-references an additional 11 articles were found, yielding a total of 70 articles. Of these, more than $50 \%$ were published during the prior decade. A total of 170 patients were described, 20 from one case series ${ }^{7}$ and 48 from another case series. ${ }^{8}$ The majority of the remaining articles consisted of individual case descriptions. Because one patient was described twice, ${ }^{9,10}$ the total number of original case descriptions was 169. Patient sex was mentioned for 162 patients; 55.6\% of them were male. Age was mentioned in 166 patients; mean age was 15.5 years. A total of 132 patients were $\leq 18$ years, with a mean age of 9 years, and 34 patients were 19 years and older, with a mean age of 40 years. Table 1 presents an overview of the many disorders, intoxications, and other conditions that have been described in the context of AIWS. Among youths, the most frequently described condition was encephalitis $(21.7 \%$ vs $1.2 \%$ among adults 


\section{The differential diagnosis of AIWS and its individual symptoms is complex, as it involves at least 3 levels of conceptualization.}

and elderly patients), with the Epstein-Barr virus being the most frequently reported pathogen (68.4\% of all cases of encephalitis). Among the group of adults and elderly patients, neurologic disorders were most frequently described (16.8\%); of all these disorders, migraine was the most prevalent condition (9.6\%). The course and outcome were described in 150 patients. In 54 patients $(36.0 \%)$ the treatment regimen was also specified; this mostly involved pharmacologic treatment aimed at alleviating the underlying condition. One patient received electroconvulsive treatment ${ }^{11}$ and another patient received repetitive transcranial magnetic stimulation ${ }^{2}$; both treatments were successful. The remaining patients received no treatment or it was unspecified. Full remission was obtained in $46.7 \%$ of all patients, and partial or temporary remission in $11.3 \%$. In chronic conditions such as epilepsy and migraine, full remission was obtained only rarely.

\section{DISCUSSION}

\section{Historical perspective}

The term Alice in Wonderland syndrome was introduced in 1955 by the British psychiatrist John Todd (1914-1987) to cover a group of symptoms "... intimately associated with migraine and epilepsy, although not confined to these disorders." ${ }^{12}$ As envisioned by Todd, ${ }^{12}$ the group comprised derealization, depersonalization, hyperschematia, hyposchematia, and somatopsychic duality, as well as illusory changes in the size, distance, or position of stationary objects in the visual field; illusory feelings of levitation; and illusory alterations in the sense of the passage of time. Incidentally, Todd was well aware that he was not the first to describe those individual symptoms. Many of them had appeared before in the literature on hysteria, ${ }^{13}$ on general neurology, ${ }^{14-17}$ and on soldiers with occipital wounds after World Wars I and II. ${ }^{18,19}$ Moreover, in 1933 and 1952, Coleman ${ }^{20}$ and Lippman, ${ }^{21}$ respectively, had already drawn comparisons between those symptoms and the experiences of Alice in Wonderland, albeit without turning the name into an eponym. Lippman ${ }^{21}$ was also the first to suggest that the bodily changes experienced by Alice might well be inspired by body schema illusions Lewis Carroll had experienced himself. Carroll (pseudonym of the British mathematician Charles Lutwidge Dodgson, 1832-1898) had migraines, and his diaries indicate that his attacks were sometimes preceded by aural phenomena. ${ }^{22}$ However, historians consider Lippman's hypothesis inconclusive, as the diaries fail to demonstrate that Dodgson experienced any aural phenomena before he wrote his book. ${ }^{23}$ An alternative hypothesis is that Dodgson had knowledge of-or perhaps had experimented with-the hallucinogenic mushroom Amanita muscaria. ${ }^{24}$ Whatever the exact course of events may have been, with Alice in Wonderland, Dodgson created a character that appealed as much to physicians as it did to the book's intended audience. And Todd, by adopting the name, chose a memorable moniker for a group of symptoms hitherto described in isolation of each other.

\section{Phenomenology}

Over the past 60 years, AIWS symptoms have come to include 42 visual symptoms (table 2) and 16 somesthetic and other nonvisual symptoms (table 3). What these symptoms have in common with each other is that they constitute distortions of sensory perception rather than hallucinations or illusions. ${ }^{25}$ Hallucinations are percepts experienced in the absence of an appropriate stimulus from the outside world, such as a voice heard in the absence of sound 
Table 2 Visual distortions (metamorphopsias) that may be experienced in the context of Alice in Wonderland syndrome

Type of metamorphopsia

Achromatopsia

Akinetopsia

Arugopsia

Chloropsia

Chromatopsia

\section{Corona phenomenon}

Cyanopsia

Dyschromatopsia

Dysmegalopsia

Dysmetropsia

Dysmorphopsia

Dysplatopsia

Enhanced stereoscopic vision

\section{Entomopia}

Erythropsia

Gyropsia

Hemimetamorphopsia

Hyperchromatopsia

lanothinopsia

Illusory splitting

Illusory visual spread

Inverted vision

Kinetopsia

Loss of stereoscopic vision

Macroproxiopia

Macropsia

Micropsia

Microtelepsia

Monocular metamorphopsia

Mosaic vision

\section{Palinopsia}

\section{Pelopsia}

Plagiopsia

Polyopia

Porropsia

Prosopometamorphopsia

\section{Characterization}

The inability or strongly diminished ability to perceive color

The inability to perceive motion

Seeing wrinkled surfaces as smooth

Green vision

Seeing things in a single hue (as in chloropsia, cyanopsia, erythropsia, ianothinopsia, and xanthopsia)

An extra contour around objects

Blue vision

Color confusion

A diminished ability to appreciate the size of objects

A change in the apparent size and distance of objects

Lines and contours appearing to be wavy

Objects appearing flattened and elongated

An exaggeration of the depth and detail of visually perceived objects

Seeing multiple images, as if perceived through an insect's eye

Red vision

Seeing an illusory, circular movement

A visual distortion of only one half of an object

Seeing colors as exceptionally bright

Purple vision

An illusory vertical splitting of objects

A perceived extension, expansion, or prolongation of objects

Objects appearing rotated (usually in the coronal plane, over $90^{\circ}$ or $180^{\circ}$ )

Illusory movement

Objects appearing 2-dimensional or "flat"

Objects appearing larger and closer by than they are

Seeing things larger than they are

Seeing things smaller than they are

Objects appearing smaller and farther away than they are

Metamorphopsia for one eye

A fragmentation of perceived objects into irregular, crystalline, polygonal facets, interlaced as in a mosaic

Illusory recurrence of visual percepts (as in polyopia, illusory visual spread, and the trailing phenomenon)

Objects appearing closer by than they are

Objects appearing as if tilted

Seeing multiple identical copies of a single image

Stationary objects appearing to move away

Apparent distortion of faces
$3(1.8)$

4 (2.4)

$1(0.6)$

1 (0.6)

$1(0.6)$

$11(6.5)$

$1(0.6)$

$3(1.8)$

No. of times (\%) described in the literature $(\mathbf{N}=169)$

9 (5.3)

$1(0.6)$

$-$

$1(0.6)$

3 (1.8)

34 (20.1)

$2(1.2)$

$15(8.9)$

2 (1.2)

76 (45.0)

99 (58.6)

7 (4.1)

$-$

$-$

3 (1.8)

3 (1.8) 
Table 2 Continued

\section{Type of metamorphopsia \\ Teleopsia \\ Trailing phenomenon}

Visual allachesthesia

Visual perseveration

Xanthopsia

Zoom vision

\section{Characterization}

Objects appearing to be farther away than they are

A series of discontinuous stationary images trailing behind a moving object

Objects appearing dislocated into the opposite visual field

An illusory recurrence of visual percepts after an object has moved out of focus

Yellow vision
No. of times (\%) described in the literature $(\mathrm{N}=169)$

39 (23.1)

$-$

$4(2.4)$

$-$

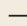

$4(2.4)$

Vision fluctuating between micropsi
microtelepsia and macroproxiopia

production or a cat seen that is not there. Illusions do have a source in the outside world, albeit one that is (often fleetingly) misperceived or misinterpreted. Thus music may be heard in the drone of passing traffic and a curtain moving in the wind may be mistaken for an intruder. Like illusions, distortions are based on sensory impressions, but they feature highly specific changes in highly specific aspects of the sensory input picture. For example, all straight lines may be perceived as wavy (dysmorphopsia), all vertical lines as slanted (plagiopsia), all stationary objects as moving (kinetopsia), or all eyes as unnaturally big (prosopometamorphopsia). Tables 2 and 3 describe the many possible variants and also how often they have been described in case reports of AIWS. Strikingly, micropsia and macropsia have been described most frequently in the literature (in 58.6\% and $45.0 \%$ of all patients, respectively), which might indicate that they are the most prevalent types of distortion but also that they are the best known and therefore studied most frequently.

The duration of symptoms of AIWS tends to be short, mostly on the order of minutes to days ${ }^{26}$; however, symptoms may also persist for years ${ }^{2}$ or even be lifelong. ${ }^{27} \mathrm{~A}$ salient detail is that after visual fixation on an object, metamorphopsias may sometimes arise after an interval of seconds to minutes. ${ }^{27,28}$ After that temporal delay, objects are perceived in a distorted manner, but during the delay the perceptual process is undisturbed. In the historical literature this phenomenon has been explained as a sign of cerebral asthenopia ${ }^{28,29}$ (i.e., an unusual fatigability of the perceptual system).

\section{Epidemiology}

No epidemiologic data on AIWS in the population at large are available. Although it is generally assumed that the syndrome is rare, clinical studies among patients with migraine indicate that the prevalence rate in this group may be around $15 \% .{ }^{23,30}$ Moreover, some studies indicate that individual symptoms of AIWS are not rare in the general population. A cross-sectional study of 1,480 adolescents $^{31}$ found a lifetime prevalence of micropsia and/or macropsia of $5.6 \%$ for males and $6.2 \%$ for females. A second cross-sectional study of 3,224 high school students $^{32}$ found 6 -month prevalence rates of $3.8 \%$ for micropsia, $3.9 \%$ for macropsia, $2.5 \%$ for protracted duration, and $1.3 \%$ for the quick-motion phenomenon. A third cross-sectional study ${ }^{33}$ of 297 individuals with a median age of 25.7 years found lifetime prevalence rates of $30.3 \%$ for teleopsia, $18.5 \%$ for dysmorphopsia, $15.1 \%$ for macropsia, and $14.1 \%$ for micropsia. This study also showed that $38.9 \%$ of the affected individuals experienced a single symptom, 33.6\% experienced 2, $10.6 \%$ experienced 3, and $16.8 \%$ experienced 4 . This buildup might indicate a common underlying etiologic process responsible for the mediation of all 4 symptoms or a stochastic process in which the presence of one symptom lowers the threshold for another one to join in. 
Table 3 Somesthetic and other nonvisual distortions that may be experienced in the context of Alice in Wonderland syndrome

Type of distortion

Aschematia

Derealization

Depersonalization

Hyperschematia

Hyposchematia

Illusory feeling of levitation

Palisomesthesia

Paraschematia

Partial macrosomatognosia

Partial microsomatognosia

Protracted duration

Quick-motion phenomenon

Splitting of the body image

Time distortion

Total-body macrosomatognosia

Total-body microsomatognosia

\section{Characterization}

Inadequate representation of the space occupied by some part of the body

Experiencing the world as unreal

Experiencing oneself as unreal

Overrepresentation of the space occupied by some part of the body

Underrepresentation of the space occupied by some part of the body

Sensation of floating in the air

Illusory recurrence of somesthetic percepts

Inappropriate representation of the space occupied by some part of the body

Experiencing a part of the body as larger than it is

Experiencing a part of the body as smaller than it is

Deceleration of psychological time

Acceleration of psychological time

Sensation of one's own body being split in 2, usually down the middle

Altered experience of psychological time

Experiencing the whole body as larger than it is

Experiencing the whole body as smaller than it is
No. of times (\%) described in the literature $(\mathrm{N}=169)$

$1(0.6)$

$17(10.0)$

$7(4.1)$

$1(0.6)$

$-$

$4(2.4)$

-

-

$12(7.1)$

$13(7.7)$

$6(3.6)$

$22(13.0)$

1 (0.6)

$3(1.8)$

$15(8.9)$

$14(8.3)$

\section{Pathophysiology}

The symptoms of AIWS are attributed to functional and structural aberrations of the perceptual system. ${ }^{34}$ On the whole, central pathology is considered the most prevalent cause; however, dysmorphopsia, for example, is also experienced in the context of retinal ablation and some other types of eye disease, and plagiopsia (visual tilt) is also experienced in the context of labyrinthine disease. ${ }^{35}$ Nevertheless, most symptoms of AIWS are attributed to centrally located neuron populations and even cell columns that respond selectively to specific types of sensory input (for vision, notably cortical areas V1-V5). Area V4 of the extrastriate visual cortex, for example, responds selectively to color, whereas area V5 responds to movement. Both areas also respond to shape and depth, but bilateral loss of function of V4 results in achromatopsia (the inability to see color) and bilateral loss of $\mathrm{V} 5$ results in akinetopsia (the inability to see motion). The inability to visually perceive vertical lines (plagiopsia) or lines under a different angle is attributed to loss of function of orientation columns that are grouped together throughout the horizontal layers of visual cortex. Similarly, various neuron populations have been identified as being responsible for mediating different types of metamorphopsia, and for other metamorphopsias educated guesses have been made. ${ }^{36}$ Sometimes this involves higherorder mismatches between larger components of the visual network, which can vary interindividually. An example of the latter situation can be found in complex types of prosopometamorphopsia, in which human faces may be perceived consistently as animal faces ${ }^{27}$ and even in an apparently straightforward symptom such as micropsia, which was found to be associated with a consistent pattern of occipital hypoactivation and parietal hyperactivation in an fMRI study. ${ }^{6}$ 


\section{Whenever treatment is considered useful and necessary, it needs to be aimed at the suspected underlying condition.}

Mutatis mutandis, the same would seem to hold true for somesthetic distortions, in the sense that functional and/or structural aberrations of specific neuron populations in somatosensory cortical areas are responsible for mediating body schema illusions such as microsomatognosia, palisomesthesia, aschematia, etc. In these cases, parts of the network located around the parieto-temporo-occipital junction are responsible, ${ }^{37}$ although here too a mismatch between higher-order components of the network as a whole may be at play, as in ischemia of distal parts of the anterior cerebral arteries that supply parts of the perceptual network responsible for integrating composite sensory data for awareness of the body schema. ${ }^{38}$ Whether similar mechanisms are responsible for mediating time distortions is as yet unknown.

\section{Etiology}

The conditions responsible for mediating the symptoms of AIWS are legion. Table 1 presents those described so far in the literature, classified into 8 main groups. One of those groups is "substance-induced," also known as hallucinogen persisting perception disorder (HPPD), ${ }^{39}$ a nosologic construct featured in the DSM- $5^{40}$ and other classifications as a separate diagnostic category that covers perceptual symptoms that arise during (or after the cessation of) the use of illicit substances. The list of conditions associated with AIWS is long and is expected to grow even longer when more cases and case series are published.

\section{Diagnosis and differential diagnosis}

AIWS does not feature in major classifications such as the ICD- $10^{41}$ and the DSM-5. ${ }^{40}$ As a consequence, in clinical practice the diagnosis of AIWS stands and falls with proper historytaking, a thorough physical (including neurologic and often otologic and/or ophthalmic) examination, and sound knowledge of the many and varying symptoms characteristic of AIWS and their possible causes. Cases with a suspected central origin should prompt auxiliary investigations including blood tests, EEG, and brain MRI scan, even though the chances of finding any demonstrable lesions are generally considered to be low. ${ }^{8}$

The differential diagnosis of AIWS and its individual symptoms is complex, as it involves at least 3 levels of conceptualization. First, the symptoms need to be distinguished from other positive disorders of perception such as hallucinations and illusions, with which they may be easily confused. Second, their most likely cause needs to be established. As table 1 indicates, many diagnoses are possible. Therefore, third, whether the diagnosed condition may be responsible for mediating the symptoms must be established. Because metamorphopsias and other distortions are also experienced by individuals in the general population, situations may arise in which the disorder diagnosed is not causally connected with the symptoms at hand or in which a therapeutic intervention turns out to be the actual cause.

\section{Treatment and prognosis}

Most nonclinical and clinical cases of AIWS are considered benign, in the sense that full remission of the symptoms can often be obtained, sometimes spontaneously and in other cases after proper treatment. However, in clinical cases with an underlying chronic condition (such as migraine and epilepsy), symptoms tend to recur in concordance with active phases of the disease, and in cases of encephalitis the prognosis may also vary. As a consequence, the need to treat requires careful assessment, proper knowledge of the natural course of the various underlying conditions that are possible, and a careful explanation to the patient of what to expect from which therapeutics under which circumstances. In many cases reassurance will suffice. Whenever treatment is considered useful and necessary, it needs to be aimed at the suspected 


\section{Take-home points}

- AIWS is characterized by perceptual distortions rather than hallucinations or illusions and therefore needs to be distinguished from schizophrenia spectrum and other psychotic disorders

- When symptoms of AIWS are transient and not associated with any other pathology, reassurance that the symptoms themselves are not harmful may suffice

- Based on the large spectrum of known etiologies and the prospect of improved outcome, I recommend auxiliary investigations to address symptom reoccurrence causing major distress or dysfunction, with or without other pathology

- In clinical cases, treatment needs to be directed at underlying conditions underlying condition. In clinical practice this mostly involves the prescription of antiepileptics, migraine prophylaxes, antiviral agents, or antibiotics. The literature indicates that antipsychotics are rarely prescribed ${ }^{7}$ and that in most cases their effectiveness is considered marginal. Moreover, when distortions are experienced as comorbid symptoms in patients with psychosis, it is important to take into account the possibility that they can sometimes be induced or aggravated by antipsychotics because of their potential to lower the threshold for epileptic activity (as has been described for risperidone). ${ }^{42}$

\section{Limitations}

The number of case descriptions of AIWS is small, especially considering the fact that the syndrome appears to be seriously underdiagnosed and that individual symptoms may be systematically neglected. This may be at least partly because international diagnostic classifications have so far refrained from including the syndrome. The operational definition of AIWS and its diagnostic criteria are in need of further development. More specifically, the question remains whether distortions in the olfactory, gustatory, auditory, sexual, coenesthetic, kinesthetic, proprioceptive, algesic, vestibular, and thermic modalities should be added to the list of possible symptoms of AIWS. More importantly, however, the validity of AIWS as an independent nosologic construct needs to be assessed, as well as its overlap with related syndromes such as HPPD (which is also referred to in the literature as "LSD-induced Alice in Wonderland syndrome" 43 ). Other limitations are the lack of systematic epidemiologic data and our limited insight into the many etiologic and pathophysiologic mechanisms possible in this context. Functional imaging techniques such as SPECT and fMRI have the potential to aid in localizing the network structures involved in mediating the symptoms of AIWS; however, so far, only 5 case reports have been published, ${ }^{2-6}$ probably because patients with longer-lasting distortions are hard to find and contrast signals in individual patients may be weak.

\section{CONCLUSIONS}

Since 1955, no more than 169 case descriptions of AIWS have been published. The literature indicates that this may be only the tip of the iceberg, with many individual symptoms of AIWS being experienced (albeit occasionally and only fleetingly) by up to $30 \%$ of adolescents in the general population. Although reassurance seems to suffice in roughly half of the clinical cases, the suspicion of a central origin of the symptoms should prompt auxiliary investigations in the form of blood tests, EEG, and brain MRI. Although firm evidence to justify these auxiliary investigations is lacking, I recommend them on clinical grounds because of the spectrum of known etiologies and the prospect of improved outcome in a substantial number of cases after adequate treatment. Treatment, if necessary, needs to be directed at the suspected underlying cause. Regarding research, much larger patient sample sizes are needed to allow for sufficient statistical power of empirical studies of AIWS and its individual symptoms. In addition, epidemiologic surveys in the population at large are needed to establish sound prevalence data. As an alternative or an adjuvant strategy, one might consider creating an international database for cases of AIWS, with special attention paid to phenomenological characteristics, diagnostic findings (including substance abuse), natural course, and treatment results. For such a database to be effective, all new cases of AIWS should be subjected to a systematic assessment, including proper history-taking, neurologic and other physical examinations, and auxiliary investigations. 
In chronic cases, functional imaging techniques may be helpful in establishing specific neurobiological correlates of individual symptoms (although there are often various practical obstacles to be overcome). AIWS is in need of proper representation in international diagnostic classifications such as the ICD (for example under the heading of "Diseases of the Nervous System, Episodic and Paroxysmal Disorders" or "Other Disorders of the Nervous System") and the DSM (preferably under a new heading called "Perceptual Disorders," which in future editions might also include other nonpsychotic perceptual disorders such as the Charles Bonnet syndrome, exploding head syndrome, and cenesthesiopathy). Last but not least, our insight into the nature of AIWS might be enhanced by network analyses of the mutual relationships of individual symptoms as well as their relationships with the perceptual networks underlying them. In the meantime, however, it is possible to carry out a careful diagnostic procedure to help this partly hidden group of patients obtain a proper diagnosis and, if possible, adequate reassurance and, if necessary, appropriate treatment.

\section{REFERENCES}

1. Carroll L. Alice's Adventures in Wonderland. London: MacMillan and Co.; 1865.

2. Blom JD, Looijestijn J, Goekoop R, et al. Treatment of Alice in Wonderland syndrome and verbal auditory hallucinations using repetitive transcranial magnetic stimulation. A case report with fMRI findings. Psychopathology 2011;44:337-344.

3. Morland D, Wolff V, Dietemann JL, et al. Robin Hood caught in Wonderland: brain SPECT findings. Clin Nucl Med 2013;38:979-981.

4. Kuo YT, Chiu NC, Shen EY, Ho CS, Wu MC. Cerebral perfusion in children with Alice in Wonderland syndrome. Pediatr Neurol 1998;19:105-108.

5. Gencoglu EA, Alehan F, Erol I, Koyuncu A, Aras M. Brain SPECT findings in a patient with Alice in Wonderland syndrome. Clin Nucl Med 2005;30:758-759.

6. Brumm K, Walenski M, Haist F, Robbins SL, Granet DB, Love T. Functional magnetic resonance imaging of a child with Alice in Wonderland syndrome during an episode of micropsia. J AAPOS 2010;14:317-322.

7. Losada-Del Pozo R, Cantarín-Extremera V, García-Peñas JJ, et al. Caracteristícas y evolución de los pacientes con síndrome de Alicia en el País de las Maravillas. Rev Neurol 2011;53: 641-648.

8. Liu AM, Liu JG, Liu GW, Liu GT. "Alice in Wonderland” syndrome: presenting and follow-up characteristics. Pediatr Neurol 2014;51:317-320.

9. Eshel GM, Eyov A, Lahat E, Brauman A. Alice in Wonderland syndrome, a manifestation of acute Epstein-Barr virus infection. Pediatr Infect Dis J 1987;6:68.

10. Lahat E, Eshel G, Arlazoroff A. "Alice in Wonderland" syndrome: a manifestation of infectious mononucleosis in children. Behav Neurol 1991;4:163-166.

11. Bui E, Chatagner A, Schmitt L. Alice in Wonderland syndrome in major depressive disorder. J Neuropsychiatry Clin Neurosci 2010;22:352.

12. Todd J. The syndrome of Alice in Wonderland. Can Med Assoc J 1955;73:701-704.

13. Charcot JM. Leçons du Mardi à La Salpêtrière. Policlinique 1888-1889. Paris: E. Lecrosnier \& Babé; 1889.

14. Veraguth O. Ueber Mikropsie und Makropsie. Dtsch Z Nervenheilkd 1903;24:453-464.

15. Bonnier P. L'aschématie. Rev Neurol 1905;13:605-609.

16. Wilson SAK. Dysmetropsia and its pathogenesis. Trans Ophthalmol Soc U K 1916;36:412-444.

17. Pötzl O. Über Anfälle vom Thalamustypus. Z Gesamte Neurol Psychiatr 1943;176:793-800.

18. Gelb A, Goldstein K. Zur Psychologie des optischen Wahrnehmungs- und Erkennungsvorganges. Z Gesamte Neurol Psychiatr 1918;41:1-141.

19. Seitelberger F. Über Phantomerscheinungen bei Thalamuserkrankungen. Wien Z Nervenheilkd Grenzgeb 1952;4:259-265.

20. Coleman SM. Misidentification and non-recognition. J Ment Sci 1933;79:42-51.

21. Lippman CW. Certain hallucinations peculiar to migraine. J Nerv Ment Dis 1952;116:346-351.

22. Podoll K, Robinson D. Lewis Carroll's migraine experiences. Lancet 1999;353:1366.

23. Restak RM. Alice in migraineland. Headache 2006;46:306-311.

24. Carmichael C. Wonderland revisited. London Miscellany 1996;28:19-28.

25. Blom JD. A Dictionary of Hallucinations. New York, NY: Springer; 2010.

26. Lanska JR, Lanska DJ. Alice in Wonderland syndrome: somesthetic vs visual perceptual disturbance. Neurology 2013;80:1262-1264.

27. Blom JD, Sommer IEC, Koops S, Sacks OW. Prosopometamorphopsia and facial hallucinations. Lancet 2014;384:1998. 
28. Willanger R, Klee A. Metamorphopsia and other visual disturbances with latency occurring in patients with diffuse cerebral lesions. Acta Neurol Scand 1966;42:1-18.

29. Pötzl O. Die Optisch-Agnostische Störungen. Leipzig: F. Deuticke; 1928.

30. Smith RA, Wright B, Bennett S. Hallucinations and illusions in migraine in children and the Alice in Wonderland syndrome. Arch Dis Child 2015;100:296-298.

31. Abe K, Suzuki T. Prevalence of some symptoms in adolescence and maturity: social phobias, anxiety symptoms, episodic illusions and idea of reference. Psychopathology 1986;19:200-205.

32. Abe K, Oda N, Araki R, Igata M. Macropsia, micropsia, and episodic illusions in Japanese adolescents. J Am Acad Child Adolesc Psychiatry 1989;28:493-496.

33. Lipsanen T, Lauerma H, Peltola P, Kallio S. Visual distortions and dissociation. J Nerv Ment Dis 1999;187:109-112.

34. ffytche DH, Howard RJ. The perceptual consequences of visual loss: "positive" pathologies of vision. Brain 1999;122:1247-1260.

35. Deecke L, Mergner T, Plester D. Tullio phenomenon with torsion of the eyes and subjective tilt of the visual surround. Ann NY Acad Sci 1981;374:650-655.

36. ffytche DH, Blom JD, Catani M. Disorders of visual perception. J Neurol Neurosurg Psychiatry 2010;81:1280-1287.

37. Ceriani F, Gentileschi V, Muggia S, et al. Seeing objects smaller than they are: micropsia following right temporo-parietal infarction. Cortex 1998;34:131-138.

38. Kew J, Wright A, Halligan PW. Somesthetic aura: the experience of "Alice in Wonderland." Lancet 1998;351:1934.

39. Litjens RP, Brunt TM, Alderliefste GJ, et al. Hallucinogen persisting perception disorder and the serotonergic system: a comprehensive review including new MDMA-related clinical cases. Eur Neuropsychopharmacol 2014;24:1309-1323.

40. American Psychiatric Association. Diagnostic and Statistical Manual of Mental Disorders, 5th ed Washington, DC: American Psychiatric Association; 2013.

41. World Health Organization. The International Classification of Diseases, 10th Revision. Geneva: World Health Organization; 1992.

42. Morehead DB. Exacerbation of hallucinogen-persisting perception disorder with risperidone. J Clin Psychopharmacol 1997; 17:327-328.

43. Lerner AG, Lev Ran S. LSD-associated "Alice in Wonderland syndrome" (AIWS): a hallucinogen persisting perception disorder (HPPD) case report. Isr J Psychiatry Relat Sci 2015;52:67-69.

Received October 11, 2015. Accepted in final form January 12, 2016.

\section{AUTHOR CONTRIBUTIONS}

Drafting/revising the manuscript, study concept or design, and analysis or interpretation of data.

\section{STUDY FUNDING}

No targeted funding reported.

\section{DISCLOSURES}

J.D. Blom received publishing royalties for Katatonie en Dissociatie (AccreDidact/Prelum, 2014), Visuele Hallucinaties en Andere Positieve Visuele Waarnemingsstoornissen (AccreDidact/Prelum, 2013), Hallucinations: Research and Practice (Springer, 2012), and A Dictionary of Hallucinations (Springer, 2010). Full disclosure form information provided by the author is available with the full text of this article at Neurology.org/cp.

\section{Related articles from AAN physician and patient resources}

\section{Neurology ${ }^{\circledR} \quad$ - Neurology.org}

Migraine trait symptoms in migraine with and without aura April 22, 2014;82:1416-1424.

Alice in Wonderland Syndrome: Somesthetic vs visual perceptual disturbance March 26, 2013;80:1262-1264. 


\title{
Neurology ${ }^{\circ}$ Clinical Practice
}

\author{
Alice in Wonderland syndrome: A systematic review \\ Jan Dirk Blom \\ Neurol Clin Pract 2016;6;259-270 Published Online before print April 8, 2016 \\ DOI 10.1212/CPJ.0000000000000251
}

This information is current as of April 8, 2016

\section{Updated Information \& Services \\ Supplementary Material}

References

Citations

Subspecialty Collections

Permissions \& Licensing

Reprints including high resolution figures, can be found at: http://cp.neurology.org/content/6/3/259.full.html

Supplementary material can be found at: http://cp.neurology.org/content/suppl/2016/04/08/CPJ.0000000000000 251.DC1 http://cp.neurology.org/content/supp1/2016/07/11/CPJ.0000000000000 251.DC2

This article cites 37 articles, 2 of which you can access for free at: http://cp.neurology.org/content/6/3/259.full.html\#\#ref-list-1

This article has been cited by 1 HighWire-hosted articles: http://cp.neurology.org/content/6/3/259.full.html\#\#otherarticles

This article, along with others on similar topics, appears in the following collection(s):

All Clinical Neurology

http://cp.neurology.org//cgi/collection/all_clinical_neurology Child psychiatry

http://cp.neurology.org//cgi/collection/child_psychiatry

Hallucinations

http://cp.neurology.org//cgi/collection/hallucinations

Information about reproducing this article in parts (figures,tables) or in its entirety can be found online at:

http://cp.neurology.org/misc/about.xhtml\#permissions

Information about ordering reprints can be found online: http://cp.neurology.org/misc/addir.xhtml\#reprintsus

Neurol Clin Pract is an official journal of the American Academy of Neurology. Published continuously since 2011, it is now a bimonthly with 6 issues per year. Copyright $\odot 2016$ American Academy of Neurology. All rights reserved. Print ISSN: 2163-0402. Online ISSN: 2163-0933.

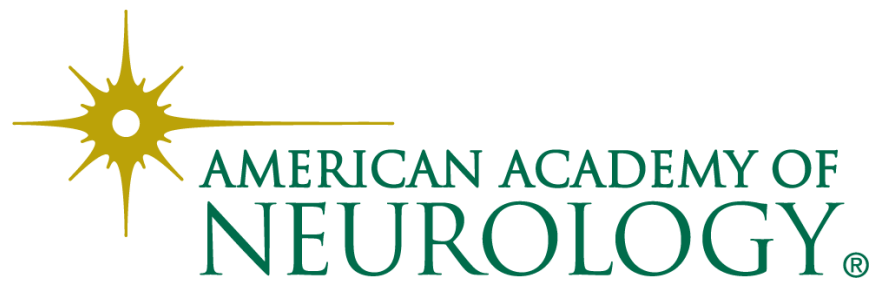

